\title{
The ontology of complexity and the neo-Schumpeterian evolutionary theory of economic change
}

\author{
Verónica Robert $^{1}$ (D) Gabriel Yoguel $^{2}$. \\ Octavio Lerena ${ }^{2}$
}

Published online: 7 July 2017

(C) Springer-Verlag GmbH Germany 2017

\begin{abstract}
Different studies have tried to find a common thread that places different evolutionary and neo-Schumpeterian contributions to economic change under one umbrella. The complexity approach can account for a set of attributes that evolutionary economics has been considering, as decentralized interaction, heterogeneous agents, bounded rationality, networks of linkages, non-linear dynamics, divergent paths, disequilibrium and emergent properties. In this regard, the complexity approach could be a theoretical and conceptual starting point that allows the integration of different contributions (Davis, 2008; Fontana, 2013). In this article, we attempt to show that complexity can also be useful to point out the profound differences between evolutionary strands. This paper analyzes how the ontological evolutionary assumptions of complexity are emphasized with different intensity by different groups of representative contributions of evolutionary economics. We propose that these differences reflect deeper issues related to two major concerns of economic theory: coordination and order vs. transformation and change of economic systems (Dosi and Orsenigo 1988). In this context, the hypothesis of the article is that complexity acts as an umbrella and at the same time as a differentiating criterion of different strands within evolutionary economics, since their ontological assumptions relate differentially to these two concerns. Using a bibliometric methodology, we identify a set of representative contributions for five strands of evolutionary economics. Additionally, we analyze how the various dimensions and attributes of complexity ontology are emphasized unevenly by each group of contributions. To show the differences, we quote fragments from contributions corresponding to the dimensions and attributes of the complexity and use a set of nonparametric tests to corroborate the significance of the differences in the frequency in which these references appear. The
\end{abstract}

Verónica Robert

vrobert@gmail.com

1 Idaes-UNSAM / Conicet. Sarmiento 2549 5to C, Buenos Aires, Argentina

2 IdeI-UNGS, Los Polvorines, Buenos Aires, Argentina 
results show that, while groups concerned with coordination are focused on heterogeneity and networks assumptions, groups concerned with transformation stress path dependence and divergent dynamics. Emergent properties are common to all of them.

Keywords Complexity · Evolutionary theory $\cdot$ Neo-Schumpeterian ·

Economic change $\cdot$ Coordination

JEL classification $\mathrm{B} 15 \cdot \mathrm{B} 52 \cdot \mathrm{O} 30$

\section{Introduction}

In recent years, there have been a series of works that have discussed the scope and limits of evolutionary economics (Vromen 2004; Davis 2008; Silva and Teixeira 2008; Dosi 2013; Fontana 2013; Hodgson and Stoelhorst 2014; Winter 2014; Witt 2014). One of the recurring issues in these discussions relates to the thematic breadth and diversity of theoretical roots involved. Evolutionary economics has been dedicated, since its origins, to the study of industrial dynamics and associated microeconomic aspects. It has also been proposed as an alternative theory in a broader sense (Nelson and Winter 1982; Dosi et al. 1988), including issues such as economic growth and development, as well as structural change. This article focuses on the evolutionary line of thought linked to Schumpeter, which we shall call "neo-Schumpeterian evolutionary economics".

The contributions of neo-Schumpeterian evolutionary economics can be divided according to the topics they address: (i) the relevance of habits and routines in learning processes and in capacity building (Nelson and Winter 1982), (ii) the competitive process and self-organization as motors for innovation and change (Metcalfe 2002), (iii) the systemic nature of innovation (Lundvall 1992; Nelson 1993; Freeman 1995), (iv) the role of demand and the mechanisms of cumulative causation as drivers of technological change (Dosi 1982; Saviotti 2001), and (v) the increasing returns associated with learning processes (David 1985; Arthur 1989).

Different studies have tried to find a common thread that allows placing different contributions under one umbrella. These works, many of them self-reflexive (e.g. Dosi 2013), reflect on the ontological foundations of evolutionary theory, trying to show some parallels between those foundations and the ontological basis of complexity given that, since its very beginnings, different sets of contributions to neo-Schumpeterian evolutionary economics were close to the complexity approach (Dosi et al. 1988; Arthur 1994; Dosi and Kaniovski 1994; Arthur et al. 1997; Arthur 1999; Cantner et al. 2000; Saviotti and Pyka 2004; Durlauf 2005; Dopfer 2005; Frenken 2006; Dopfer and Potts 2009; Potts 2010; Foster and Metcalfe 2003; Hodgson 2004; Arthur 2009; Arthur 2014; Boschma and Martin 2010; Antonelli 2011; Wilson and Kirman 2016). In this regard, the complexity approach can account for a set of attributes that evolutionary economics has been considering, including decentralized interaction, heterogeneous

\footnotetext{
${ }^{1}$ We refer by evolutionary economics to a large heterodox and heterogeneous tradition ranging from the old North American Institutionalism to contributions of the Santa Fe School on complexity. By neoSchumpeterian evolutionary scholars, we refer to the authors who produce within the International Schumpeter Society, either in the Journal of Evolutionary Economics or at the bi-annual conference.
} 
agents, bounded rationality, networks of linkages, non-linear dynamics, divergent paths, disequilibrium and emergent properties.

Several studies have suggested that the complexity approach could be both a theoretical and conceptual starting point that would allow the integration of different strands of neo-Schumpeterian evolutionary economics (Davis 2008; Fontana 2013). The objectives of this article are: (i) to show that complexity can also be useful to point out the profound differences between them and the divergent paths that can arise in the coming years, and (ii) to analyze how ontological assumptions of complexity are emphasized with different intensity in each of five major topics of the literature mentioned before. We propose that these differences reflect deeper issues related to the two major concerns of economic theory: coordination and transformation (Dosi and Orsenigo 1988).

In this article, it is argued whether the degree of interest in coordination and transformation is emphasized in evolutionary academic production fairly and considerably. Particularly, we propose that dimensions and attributes that express an ontology of complexity will allow us to carry out a detailed analysis of the differences between strands of evolutionary production in terms of coordination and transformation. In this context, the hypothesis of the article is that complexity can act as umbrella and at the same time as a differentiating criterion of the groups, as their ontological assumptions relate differently to these two concerns.

The paper is organized as follows. In Section 1, based on different definitions of complexity provided by evolutionary neo-Schumpeterian authors, we classify the ontological assumptions of complexity in four dimensions and 14 attributes. In Section 2, we depict the five major topics of evolutionary economics that correspond to the strands mentioned above. We also explain in this section how they are related to the evolutionary epistemological premises: realism, open-ended dynamics and non-reductionism (Foss 1994; Dosi and Orsenigo 1988; Dosi and Winter 2002; Dosi 2013; Hodgson 2004). In the same section, using a bibliometric methodology, we identify a set of representative contributions of strand. In Section 3, we analyze how the various dimensions and attributes of complexity ontology are emphasized differently by each group of contributions. To show these differences, we quote fragments from contributions corresponding to the dimensions and attributes of the complexity, and use a set of nonparametric tests to corroborate the significance of the differences in the frequency in which these references appear. The discussion of the main results is presented in Section 4 and the conclusions in Section 5.

\section{Towards an evolutionary ontology of complexity}

Economic ontology deals with the study of "economic realm", that is, those parts or aspects of the universe that are the object of the economy (Mäki 2001; Potts 2010). The boundaries of economic realm are not completely clear or fixed, as there are competing and changing perceptions about how to define and enclose them. These borders are essentially disputable and refer to the ontological commitments that economists assume. These nuances and disagreements can be captured by investigating how different contributions put emphasis on different ontological dimensions. 
In this section, by exploring complexity definitions found in evolutionary economic literature, we identify a set of attributes and dimensions of an evolutionary ontology of complexity. ${ }^{2}$ It is an evolutionary ontology of complexity since it bonds together different aspects of the economic realm that neo-Schumpeterian evolutionary authors have been interested in, such as self-organization (Martin and Sunley 2007; Metcalfe 2010), out of equilibrium and nonlinear dynamics (Saviotti and Pyka 2004; Dosi et al. 2010; Arthur 1989; Arthur 1994), circulation and generation of knowledge in networks (Cowan and Jonard 2004; Potts 2000; Dopfer et al. 2004) and emergent properties.

In this context, a wide range of definitions can be found in the literature depending on specific needs.

Some authors provide definitions of complexity that describe a complex system by its final state, although it does not mean a steady state, since it is open to endogenous changes. For example, Rosser (1999) and Holt, Rosser and Colander (2011) quote the definition of Day (1994) where a system is complex if it tends, endogenous and asymptotically, to something different from a fixed point, a limit cycle or an explosion. In this case, the definition is very precise but it is circumscribed to the evaluation of the system by its results, not by its composition and characteristics. Potts (2000) defines complexity as an intermediate space between order (absence of connections among components) and chaos, which means that all the components are connected. From an Austrian perspective, Potts (2000) considers an economy as a complex system of complex systems made by bounded, partial and incomplete connections among nodes. Earl and Wakeley (2010) explore the scope of Potts's claim and emphasize the incompleteness of economic systems. According to Arthur (2014), a complex system is such that the interacting elements that constitute it react (change or adapt) to the overall patterns they build by themselves and in which these reactions reconfigures those patterns. In the recursive loop between micro behavior and overall patterns is where complexity appears.

Other authors offer definitions that take the form of a list of attributes that a complex system must meet. The selection and the way in which these attributes are interconnected depends on their ontological assumptions. Foster and Metcalfe (2003) define a complex system as a network structure. First, its linkages allow information and knowledge to circulate among components; second, its structure is modular and decomposable; and finally, it is open to changes in components and interactions. Dopfer et al. (2004) define a system as complex when it exhibits modularity, openness, and hierarchy. It is modular because it is formed by a set of specific parts, functional and connected. It is open because the parts interact with some degrees of freedom and can therefore continually change their connections. Finally, it is hierarchical because each module is a complex system by itself. ${ }^{3}$ Kirman (2010) and Helbing and Kirman (2013) give a definition of complexity that emphasizes also the relevance of interactions between system components. According to them: (i) the connections between heterogeneous components are incomplete and each component has a limited number of connections to others in the

\footnotetext{
${ }^{2}$ We mean complexity attributes and dimensions as categories that lie at the level of meta-theory and not simply as analytical choices at the level of theory and its representation.

${ }^{3}$ As Simon (1962) stressed, given the properties of the parts and the laws of their interaction, it is not a trivial matter to infer the properties of the whole.
} 
neighborhood; (ii) the system's behavior cannot be understood from the properties of its components, but rather from the interactions between them; (iii) the system may exhibit emergent properties such as network structure, the heterogeneity of components, and the rules that guide the components' behavior; iv) the system behavior is often counter-intuitive and is hard to control in a centralized or topdown fashion because the components cannot act independently and will often fail to behave as they wish; v) the feedback and unexpected side effects are common; vi) the system cannot be strictly optimized in real time, even with the biggest supercomputers and vii) the system may spend long periods of time far from equilibrium and may have multiple unstable equilibria. Likewise, Arthur et al. (1997) quote six key features of complexity applied to economic systems: i) heterogeneous agents interact with each other within a specific local environment in a given space; ii) the absence of a global controller that can exploit all the opportunities or interactions of the economy, although there may be weak global interactions; iii) a hierarchical organization with many intersectoral interactions; iv) continuous adaptation through learning and evolutionary agents; v) continuous innovation, new markets, technologies, behaviors, and institutions that create new niches within the system; and vi) non-equilibrium dynamics with either no equilibrium states or multiple ones instead, which are unlikely to reach a global optimum. From the evolutionary geography perspective, Martin and Sunley (2007) stress the following features: i) the distributed nature of the systems, ii) the several scales of analysis, iii) the systems are open to novelty that comes from environment, iv) there are non-linear dynamics and feedbacks between components, v) a complex system cannot be decomposable or its decomposability is limited, vi) the system exhibits emergence and self-organization, vii) the components are adaptive and they interact with the environment, and viii) the system is not deterministic or traceable.

Following, we provide a broad definition of complexity that contains the abovementioned ones. Our definition considers 14 common attributes included in those definitions bonded together in four dimensions: (i) micro-heterogeneity; (ii) network architecture; (iii) non-linear interactions, feedbacks, and divergence; and (iv) emergent properties (Robert and Yoguel 2016). The four dimensions can be articulated in a single definition such that complex systems can be said to be made up of heterogeneous interacting components (agents) located within a network of connections that exhibit emergent properties derived from the non-linear relationships and positive feedback (see Table 1).

Micro-heterogeneity refers to variability at the component level. The economic complex systems that neo-Schumpeterian authors have in mind are made up of economic agents endowed with bounded rationality that are heterogeneous in terms of their capabilities, habits, routines, and performance. This micro-variability is endogenous, since each component has the capacity to generate novelty — creativity — and the ability to learn from the environment, and each can change its behavior in order to fit with the environment. This micro-variability will be reduced through the selection process and regenerated continuously based on innovation. Within this framework, this attribute helps to understand coordination of heterogeneous agents interacting in a decentralized manner. The prominence of the dynamic that occurs at a micro scale proves detrimental in relation to the analysis of aggregate phenomena that can manifest in divergence between systems. 
Table 1 Four dimensions of an evolutionary ontology of complexity

Ontological assumptions of complexity

\begin{tabular}{ll}
\hline Dimensions & Attributes \\
\hline I. Micro-heterogeneity & 1 Heterogeneous agents with creative capacity \\
& 2 Learning and adaptation. Routines. \\
& Capacities and behavior heterogeneity \\
II. Network Architecture & 3 Linkages between components \\
& 4 Network topology (hierarchy and decomposability) \\
& 5 Partial and local information. No global controller \\
& 6 Network externalities \\
& 7 Multiple equilibria \\
& 8 Positive feedbacks \\
& 9 Co-evolution \\
& 10 Far-from-equilibrium dynamics \\
& 11 Indeterminacy and uncertainty \\
& 12 Irreversibility. Path dependency \\
13 Heterogeneity of systems. Divergence & 14 Emergent properties \\
\hline IV. Emergent properties & \\
\hline
\end{tabular}

Source: Authors' elaboration based on the cited works

The second dimension means that agents are located in a network of interactions. This explains why information is local and contextual. The architecture of interactions in complex systems presents two main features: (i) hierarchy, in the sense put forward by Simon (1962 and 1969), according to which complex systems are composed of other subsystems that are also complex; and (ii) modularity, which means that interactions within subsystems are denser than interactions between them (Langlois 2003). The latter makes complex systems resilient to a certain extent, since they are able to absorb exogenous shocks and remain functional. In complex systems, global interactions are possible - each component simultaneously exchanges information with the rest of the system's components - but these tend to be weaker than local interactions - each component exchanges information with neighboring components in the multidimensional space (Antonelli 2011). Thus, the prevailing partial information prevents the presence of a global controller, although coordination is possible through the distributed functioning of the systems. By definition, complex systems exhibit a stable macro-behavior on the basis of micro-instability, because the dimension network architecture explains the emerging order. Dopfer (2012) explicitly dealt with the problem to integrate neo-Shcumpeterian novelty driven process theory with structure focused complexity theory. The acknowledgement of the existence of incomplete networks is directly associated with the concern of circulation and awareness of such networks, key in the coordination processes between heterogeneous and decentralized actors. From this perspective, distinctive types of courses arise on a meso or macro scale. Hence, the matter of transformation occupies a less relevant place than the one of order. The dynamic coherence of economic systems in conditions of technical change 
"is the outcome of particular 'architectures' or forms of 'regulation"” (Dosi and Orsenigo 1988 p. 32).

According to the third dimension, complex systems are characterized by non-linear interactions, positive feedbacks, disequilibrium and divergence. Interacting heterogeneous agents are located in a network architecture that exhibit the afore-mentioned properties. This means that they share and interchange tangible and intangible assets. When agents introduce an innovation, it can trigger a cascade of changes, since the components of a complex system are interconnected with one another. The adoption of a given technology will require learning and further innovations, which in turn leads to improved practices that can be adopted. These positive feedbacks in innovation processes show reinforcing interactions between co-located agents, which lead to non-linear dynamics. Since connection networks are incomplete (local interactions prevail over global ones), feedbacks may generate divergent paths between subsystems and lock-in situations. Positive feedbacks make complex systems non-ergodic, which means that systems have a memory. Therefore, different initial conditions and reinforced interactions will lead to idiosyncratic path dependence, and even to divergent paths. This aspect is linked to a considerable extent with transformation. The attributes inside this dimension work in a systematic manner. They lead to divergent trajectories and thus endogenous change processes derived from positive feedbacks, coevolution, far-from-equilibrium dynamics, indeterminacy, uncertainty, irreversibility, and path dependency.

Finally, emergent properties are the result of interactions among agents at different scales (layers). A property is said to be an "emerging property" if its nature and existence depends on nodes interacting in lower levels, but cannot be derived from the latter levels. The fact that complex systems are present on various scales of space and time means that the results of each scale cannot be derived linearly from lower scales, each of which show specific attributes. Macroscopic regularities based on micro-scale variability are emergent properties of the systems. Examples of this are divergent paths, lock-ins, and cascades of changes. Emergent properties are the key attributes of any complex system. Since there are emergent properties, the system is non-reducible.

Unlike previous dimensions, it is not possible to assign a direct association between the dimension of emergent properties and concerns of order and transformation. Nevertheless, due to the fact that there is a wide range of phenomena that can be considered as emergent property, this dimension will get closer to transformation and coordination in accordance with the type of phenomena analyzed at a particular moment. Furthermore, if ontological premises bounded to coordination are considered (first two dimensions), it is possible to assume, on the one hand, that emergent properties refer to phenomena such as order, selection, rules, routine, and so on. In contrast, when emergent properties refer to phenomena such as structural change or development, it is then that ontological premises linked to the third dimension (related to transformation) are considered. In this sense, the relation between emergent properties and the two concerns depends entirely on the importance assumed by the first three complexity dimensions.

As a whole, the four dimensions could be seen as the ontological assumptions of complexity. As we will discuss below, these dimensions are emphasized differently in the work of several authors of evolutionary and neo-Schumpeterian economics. 


\section{A possible taxonomy of evolutionary contributions}

Neo-Schumpeterian evolutionary economics, as it was broadly defined in the introduction, has been developed around the five major topics: (i) the habits and routines as a form of behavior and learning in organizations (hereinafter, habits and routines); (ii) the processes of competition and their role in the emergence of innovation (hereinafter, self-organization); (iii) the systemic nature of innovation and the role of interactions in the processes of learning and innovation (hereinafter, innovation systems); (iv) the role of demand and the mechanisms of cumulative causation between market expansion and improved efficiency resulting from the division of labor (hereinafter, cumulative causation); and (v) the issues of increasing returns associated with feedbacks that can lead to lock-ins (hereinafter, increasing returns).

Dropping the axiomatic prospects and getting closer to specific and concrete problems drawn from observation, the five strands share a distinctive set of three epistemological premises. Evolutionary theory starts from the idea that explanations should be realistic (Foss 1994), focused on open-ended dynamics (Dosi 2013; Dosi and Winter 2002) and non-reductionist (Hodgson 2004). In terms of realism, evolutionism states that the process of building the theory must begin with an "appreciative vision" (Nelson 1991) and requires rejecting the axiomatic approach of assumptions. From this perspective, the notion of bounded rationality (Simon 1972), which is central and covers multiple dimensions, manifests itself in the existence and persistence of heterogeneity. The premise of open-ended dynamics assumes that the economic system is embedded in a process that occurs historically and in real-time, characterized by radical uncertainty, path dependence and irreversibility, so that prediction is not feasible and explanation should be based on a description of open-ended process. Finally, nonreductionism alludes to the fact that the aggregate does not follow linearly from observing isolated parts, as individual actions have macro effects that are difficult to predict; therefore, it is required that the analysis is approached with layers (micro meso - macro).

The topic habits and routines refers to those works interested in learning processes both at the firm level and in the behavior of economic agents and institutions. This topic comes from a set of assumptions such as bounded rationality and environmental uncertainty, capacity building, and the organization's perception of preferences and representations of the world. This routinized behavior is coherent with habit-driven behavior, in which habits are stressed over rational choice. These habits are defined locally, depending on the scope of the actors' connections. Works concerned on habits and routines have a background in industrial organization, the theory of the firm, management, and the American institutionalism that posed coevolution between institutions, habits and routines. The premise of realism in this topic requires the recognition of the phenomenon of bounded rationality and the existence and persistence of heterogeneity, which leads to the need to open the black box of the firm. Meanwhile, the emphasis on learning processes and the accumulation of capabilities show their interest in explaining innovation as a dynamic phenomenon. Lastly, the theory of the firm, developed within this topic, is essentially non-reductionist as seen in the idea that the capabilities and routines of organizations do not equal the sum of its members.

The second topic — self-organization - is related with evolutionary and Austrian roots. The former can be seen in the interest in explaining population dynamics driven 
by variation, selection, and retention. The latter is shown in its explanation of the economy as an endogenous result of decentralized disequilibrium interactions among system components. Within this group, competition is seen as an economic process in which multiple actors interact from specific channels and continuously correct their behavior in a process of open-ended experimentation. This positively implies the possibility of excluding the idea that competitive process ends in a static equilibrium. In this sense, this topic takes into account both the premise of realism and the openended dynamics. At the same time, interactions between actors in the competition process may involve, in some cases, feedbacks leading to nonlinear relationships that prevent reductionist explanation whatsoever.

The topic innovation systems emphasizes the systemic dimension of innovation and technological change based on concepts such as local, sectoral, and national innovation systems. It places innovation and learning process in a central position, adopting a holistic and interdisciplinary approach. It also employs a historical perspective analyzing concrete experiences of economic development. Realism originates from the importance given to interactions understood as specific channels of the flow of knowledge between actors that breaks away from the idea that the only possible interaction is global and is derived from the price system. What is more, open-ended dynamics can be seen in the importance given to the divergent paths of systems over time, especially in the works on local and sectoral innovation systems. Finally, nonreductionism can be seen in the presence of positive feedbacks between components and the effect that these feedbacks have on the aggregate pattern emanating from individual interactions.

The fourth topic is related to cumulative causation as a feedback and co-evolution process between aggregate variables. Although it is focused on economic aggregates, it also recognizes the relevance of micro- and meso-dynamics. This strand emphasizes the complementarity of Keynesian, Schumpeterian, and Kaldorian sources of growth and absolute advantages in determining the specialization on international trade. The presence of persistent heterogeneity in preferences, endowments, routines, and performance, and the immanent possibility of novelty are taken as two strong assumptions. In this group, the pursuit of realism can be found in the collection of a set of stylized facts on growth, trade and technological development. While the open-ended dynamics is evident in the importance of co-evolution between Keynesian, Schumpeterian and Kaldorian sources of growth, the non-reductionism is appreciated in the mechanism of cumulative causation. This set of dimensions is reflected in the interest shown in the process of structural change.

Finally, the fifth topic, that we call increasing returns, is motivated in explaining empirical phenomena related to technology diffusion and technological lock-in. For this purpose, this strand appeals to complexity and focus especially on: i) historical studies, ii) the identification of data patterns that are consistent with some of the features of complex environment (power law) and iii) social interactions. Specially, it is focused on analyzing decentralized interactions at the micro level and the feedback and nonequilibrium dynamics derived from them. These feedbacks lead to the presence of increasing returns and divergent paths among systems. Although the contributions of this group are characterized by a special interest in formalizing and, in particular, by the use of some mainstream epistemological assumptions (including utility maximization), the formalization proposed is by origin an empirical phenomenon that is studied from a 
historical and qualitative perspective. In this broader sense, its proximity to the premise of realism is evident and is preceded by observation. From the perspective of the premise of open-ended dynamics, positive feedback and network externalities as a source of increasing returns give way to path-dependency.

\subsection{An empirical approach to identifying representative contributions for each strand}

In order to identify the relevant contributions of literature to each of the five aforementioned major topics, we have developed an ad hoc methodology that allowed us to select a number of relevant articles published after the book An Evolutionary Theory of Economic Change (Nelson and Winter 1982), which is considered the reestablishment of evolutionary thinking in economics.

First, we selected 15 journals that had published articles on evolutionary neoSchumpeterian economics over the last 30 years. We included the main journals on evolutionary economic thinking, such as the Journal of Evolutionary Economics (JEE) published by the Schumpeter Society and Journal of Economic Issues (JEI) published by the Association for Evolutionary Economics. We also included some journals on industrial dynamics and corporate change, such as: Research Policy (RP), Industrial and Corporate Change (ICC), Economics of Innovation and New Technologies (EINT), Structural Change and Economic Dynamics (SCED), Industry and Innovation (II), and Technology Analysis and Strategic Management (TASM). A set of mainstream journals were also taken into account, since some of the most cited papers on evolutionary thinking were published there. We included the Journal of Economic Literature (JEL), American Economic Review (AER) and Journal of Economic Perspectives (JEP), published by American Economic Association and the Economic Journal (EJ), published by the Royal Economic Society. Finally, we included relevant journals on heterodox economics such as Cambridge Journal of Economics (CJE). ${ }^{4}$ Finally, we selected two journals related to management, Journal of Economic Behavior and Organization (JEBO) and Harvard Business review (HBR). We are aware that, by leaving out of the selection the works published in books or book chapters, we have probably excluded valuable and important contributions to evolutionary economics. However, we consider that this decision to constrain the search to articles published in academic journals can be justified on the basis of three reasons: 1) the main one is based on searchability criteria, since there are more databases that collect articles in peer-reviewed academic journals with different measures of impact factor than those collecting books; 2) quality of the refereeing process is better guaranteed in articles than books; and 3) frequently, contributions that have been published in books also appear in academic journals in shorter version.

Second, we proposed a series of keywords contained in the descriptions of each major topic and variations thereof. (See Table 4 in the Appendix.) We conducted several searches on Econlit to identify eligible contributions in each of the selected journals. The procedure involved choosing a set of keywords for each major topic. Keywords were selected in order to explicitly account for the distinctive features of the groups, while being independent of the terms used to label the attributes of complexity.

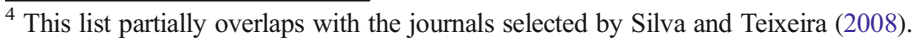


Third, using Econlit, ${ }^{5}$ we performed several searches in the selected journals. The key words proposed for each topic allowed us to designate the papers in five groups. We identified more than a hundred articles in the five major topics. Then, we proceeded to discard those articles that failed to achieve the following conditions. In the first place, being cited more than 100 times according to Google Scholar. ${ }^{6}$ In the second place, the first author having more than 20 papers published in journals, books chapters and proceedings compiled by Econlit.

Using these criteria, we kept 45 articles. We validated this list with several sources: e.g., syllabuses of courses on innovation theory in the main postgraduate programs and references made to them by the same 45 articles. In the course of this process, some missing authors called our attention to and led us to include five additional articles, mostly published in management journals not in Econlit. ${ }^{7}$ Accordingly, we asked them to comply with the same conditions as the rest of the papers.

We kept 50 articles that all together made up five groups of contributions where each one corresponded with the five topics. Eleven of them corresponded to habits and routines, most of them published by ICC and mainstream journals. Ten of them correspond to self-organization, mostly published by JEE. Sixteen articles on innovation systems, mostly from the RP. Seven articles were identified on cumulative causation, mostly from the CJE and JEE, and, finally, six articles for increasing returns, mostly from mainstream journals. The 50 selected papers are presented in Table 5 of the Appendix. In that Table we report authors, title, journal name and publishing organization.

As a result of this methodology, we approach the five major topics through the selected contributions.

In order to test how these contributions relate to one another beyond the grouping criteria based on key words, we built a weighted network using the 50 contributions and their references (Fig. 1). We define a proximity index between two contributions, $\mathrm{P}_{\mathrm{ij}}$, as the minimum proportion of common references to scholars between any $\mathrm{i}$ and $\mathrm{j}$ contributions. Mathematically, $\mathrm{P}_{\mathrm{ij}}=\min \left\{\mathrm{n}\left(\mathrm{C}_{\mathrm{i}} \cap \mathrm{C}_{\mathrm{j}}\right) / \mathrm{n}\left(\mathrm{C}_{\mathrm{j}}\right) ; \mathrm{n}\left(\mathrm{C}_{\mathrm{i}} \cap \mathrm{C}_{\mathrm{j}}\right) / \mathrm{n}\left(\mathrm{C}_{\mathrm{i}}\right)\right\}$ where $n\left(C_{i} \cap C_{j}\right)$ is the quantity of common elements between references to scholars made by contributions $i$ and $j$ (number of authors quoted by both contributions), $n\left(C_{i}\right)$ is the quantity of authors quoted by $i$ and $n\left(C_{j}\right)$ is the quantity of authors quoted by $j$. The resulting adjacence matrix, composed by the $\mathrm{P}_{\mathrm{ij}}$, is symmetric. It is worth noting that the 50 contributions refer to more than 1500 authors. Among them, Nelson, Dosi, Winter, Freeman, David, Pavitt, Lundvall, Metcalfe, Rosenberg, and Teece were the most cited authors. The average value of the $\mathrm{P}_{\mathrm{ij}} \mathrm{s}$ is 0.081 and they range from 0 to 0.41 . Among the 2500 possible pairs of contributions, only 96 show a proximity value of zero, and the weighted network exhibit a single and large component. This means that there is a high degree of linkage between the selected contributions weather they belong or not to the same strand.

\footnotetext{
$\overline{5}$ This database indexes over 1600 journals. Also, it collects books, collective volume articles, dissertations, working papers in economics, and full-text book reviews. Each record has information on title, authors, source (type of document, publication name, editor, and ISBN), an abstract and publication date.

${ }^{6}$ Given the fact that the base we used (Econlit) did not allow us to see the citations obtained by each publication, we decided, for this specific purpose, to use Google Scholar instead.

${ }^{7}$ The additional journals considered are: i) Administrative science quarterly, ii) Strategic Management Journal, iii) Organization science, iv) Technology in society, and v) Washington Quarterly.
} 


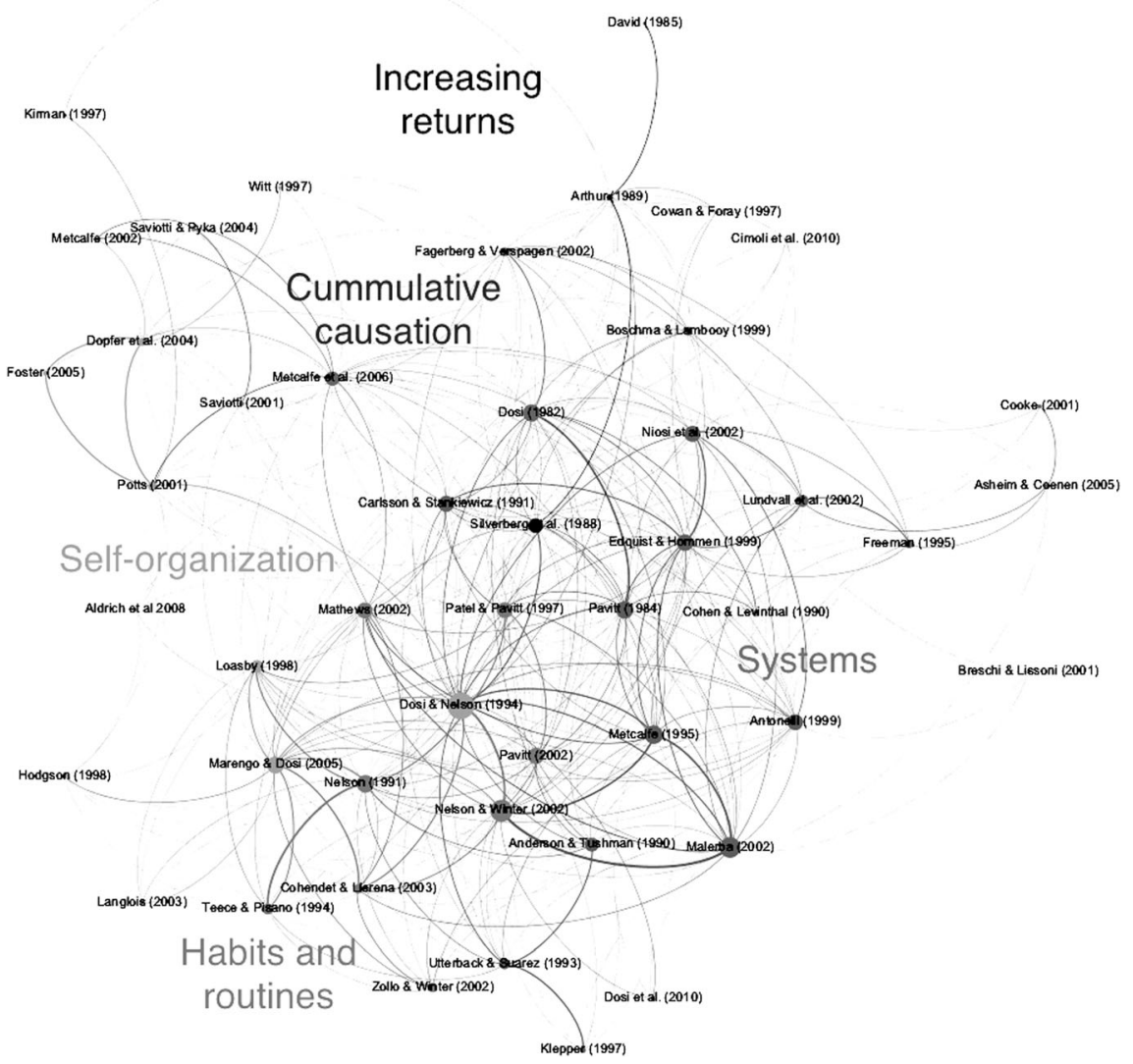

Fig. 1 Groups in the contributions network. Note: Different strands show in different shades of grey. Form lighter to darker: Habits and Routines, Self organization, Systems, Cumulative Causation and Increasing Returns. The size of the nodes is according to their degree and the width of the edges reflects their weight. Source: Own elaboration based on the 50 neo-Schumpeterian evolutionary contributions

Nevertheless, the linkages distribute unevenly between different subsets of contributions. In order to analyze this distribution, we apply two different algorithms of communities (modularity and Markov clustering algorithms) to the weighted network. We obtain two alternative grouping criteria to compare with the criteria of the five strands. We find that the groups obtained by the two algorithms overlap at least in a $43 \%$ the strand grouping criteria and, in some cases, it reaches to $100 \%$ (see Table 6 in Appendix). That means that contributions within a strand tend to show more connected each other than contributions between different strands, showing that the proposed grouping criterion based on strands is relevant.

Finally, using a force-directed layout (Jacomy et al. 2014), we graph the weighted network, discarding all those edges with weight below 0.112 . This threshold is such that it holds the entire network within a single component. We color the nodes according to their belonging to each strand. In Fig. 1, it can be seen that the contributions belonging to a same group are closer to one another than are contributions from different groups. 


\section{Evolutionism-cum-complexity: Common elements, and conceptual differences}

In this section, we focus on the degree of agreement of each evolutionary major topic with the four dimensions and the 14 attributes of complex systems ontology defined in section 1 (see Table 1). To do this, we look for explicit references (quotations) to each of those attributes in the 50 selected papers. This exercise allows us to collect specific quotations to each of the attributes of the ontology of complexity. ${ }^{8}$ Then, we calculate the proportion of contributions from each major topic that make explicit references to them (see Table 2). It is interesting to note that, while some of the selected contributions resort to the literature of complex systems, others do not. However, due to the closeness in how to understand and address the problems studied, these references can be found in all the selected papers. Altogether, we extracted 394 quotations with concrete references to the different attributes contained in Table 2. Some of those quotations are used in the description of the groups. The ratios presented in Table 2 are derived from evaluating the incidence of each attribute in each group of contributions. This procedure involved performing a content analysis on the selected articles in order to determine whether each attribute was present (1) or absent (0). ${ }^{9}$

Additionally, we estimated two sets of tests of the hypothesis. First, a nonparametric test (Kruskal - Wallis) that establishes whether the groups come from different populations and, therefore, allows us to identify the existence of statistically significant differences in attributes between groups. In other words, rejecting the null hypothesis would affirm that significant differences exist in the treatment that the different groups have towards each of the 14 attributes of complexity. Second, the pairwise test of comparison of means (after estimating the Anova test), which allows to establish whether there are statistically significant differences in each pair of the groups considered in isolation. Hence, even if there are no significant differences according to the Anova table, differences between a pair (or various pairs) of groups of contributions may have likely emerged. ${ }^{10}$

For the remainder of this section, we use Table 2 to account for the specificities of each group in terms of the relative importance they attach to the different attributes of complexity. A set of collected quotations are used to show to what extent each of the groups is close to each dimension of complexity and to clarify the differences between groups of evolutionary contributions.

The table shows that, while some attributes of the ontology of complexity are transversal to different groups -either because they are highlighted by all groups, or because they are not nearly present-, other attributes are collected differentially by

\footnotetext{
${ }^{8}$ For example, specific references to heterogeneous agents with creative capacity, linkages between components and positive feedbacks, among others.

${ }^{9}$ In the website https://sites.google.com/view/ontologyofcomplexity/, we published a set of resources that account for the procedure and intermediate steps that gave rise to the obtained results. The grid with the content analysis results at the level of contributions is available on the above-mentioned website, as well as a collection of quotations that emerged as an intermediate product in the content analysis process.

${ }^{10}$ This is a particular exercise that shows the possible links existing complexity and evolutionary economics, pursuing the main goal to show differences among strands. There are works focused on integration, instead (Fontana, 2013 and Davis 2008).
} 


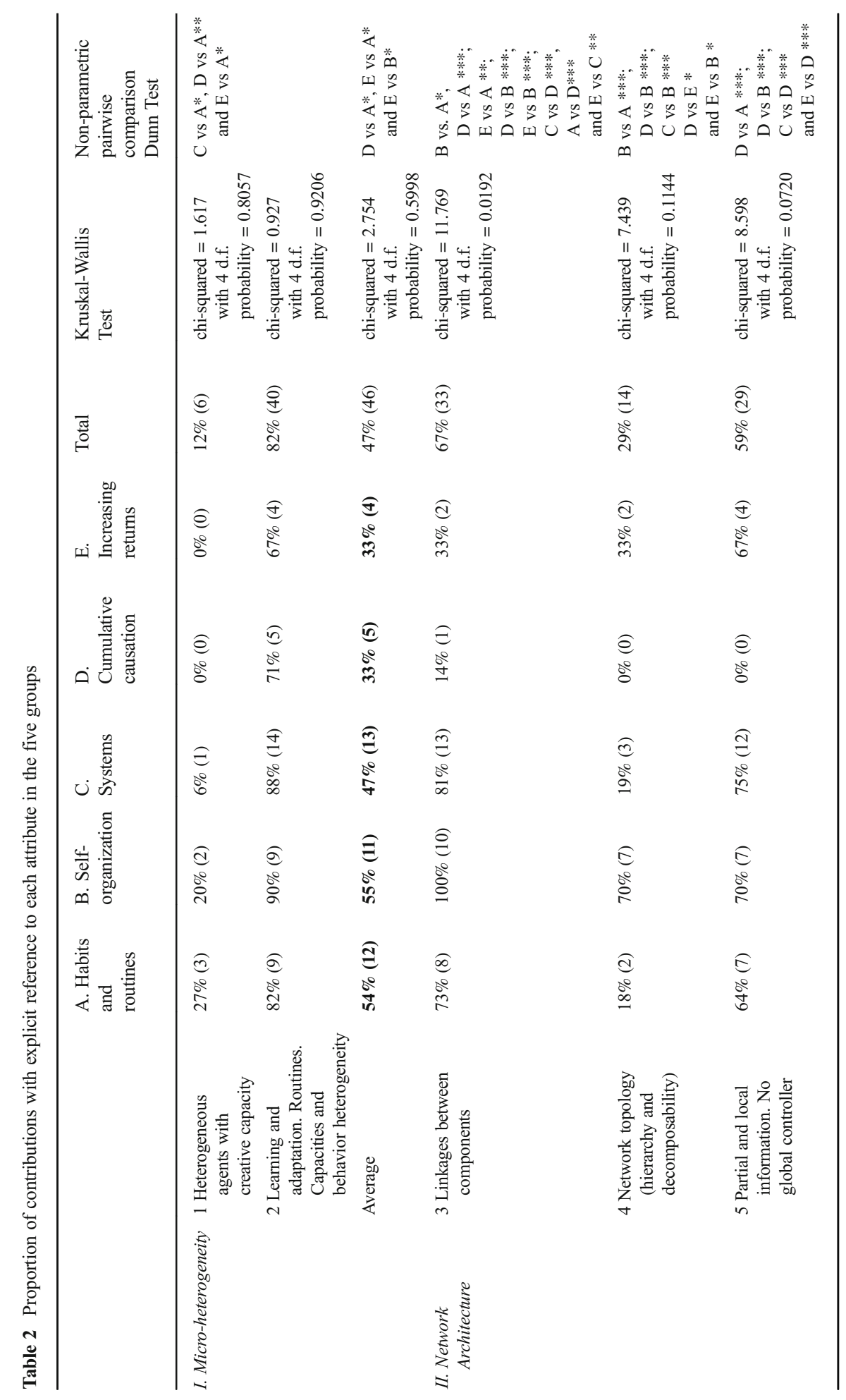




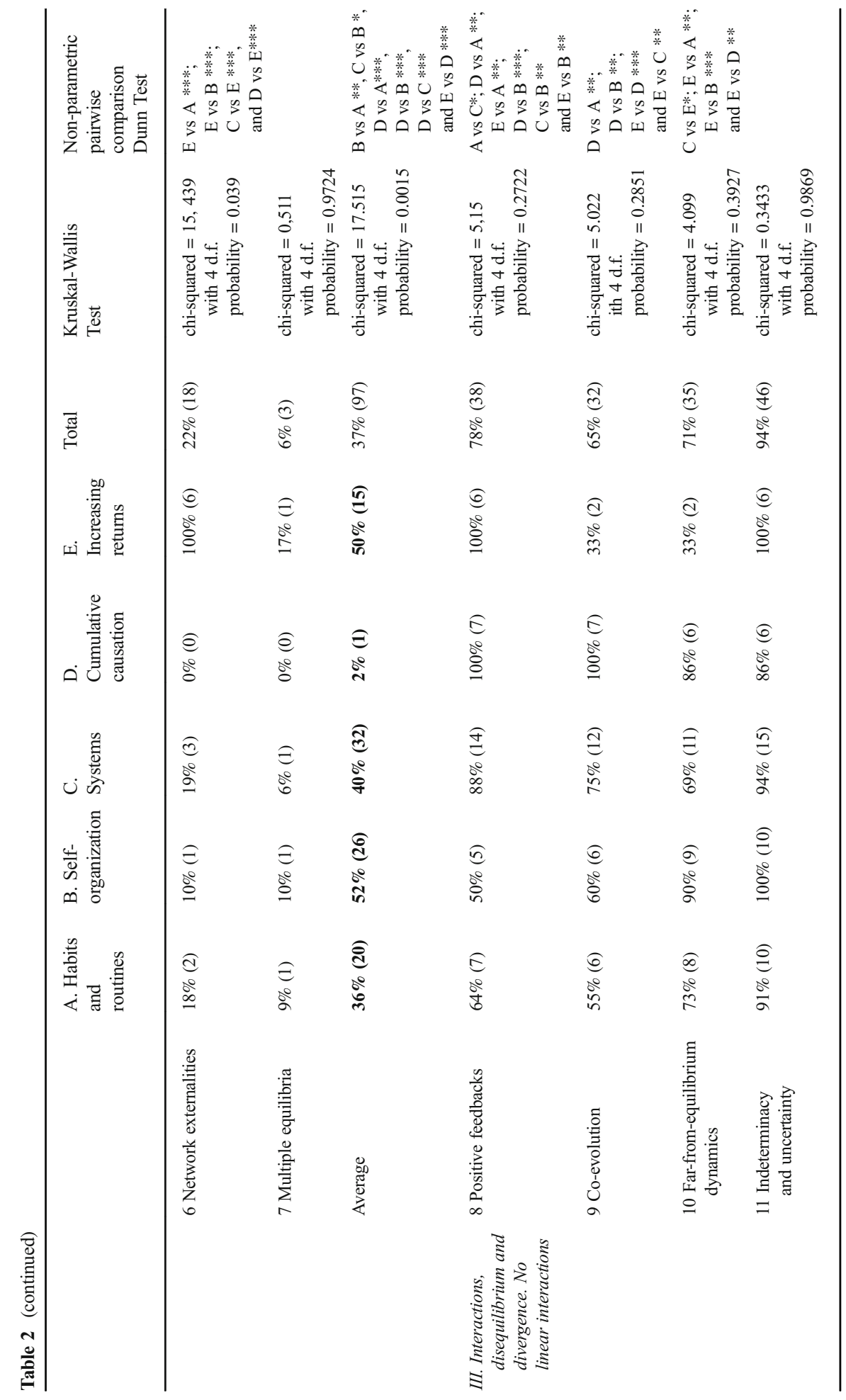




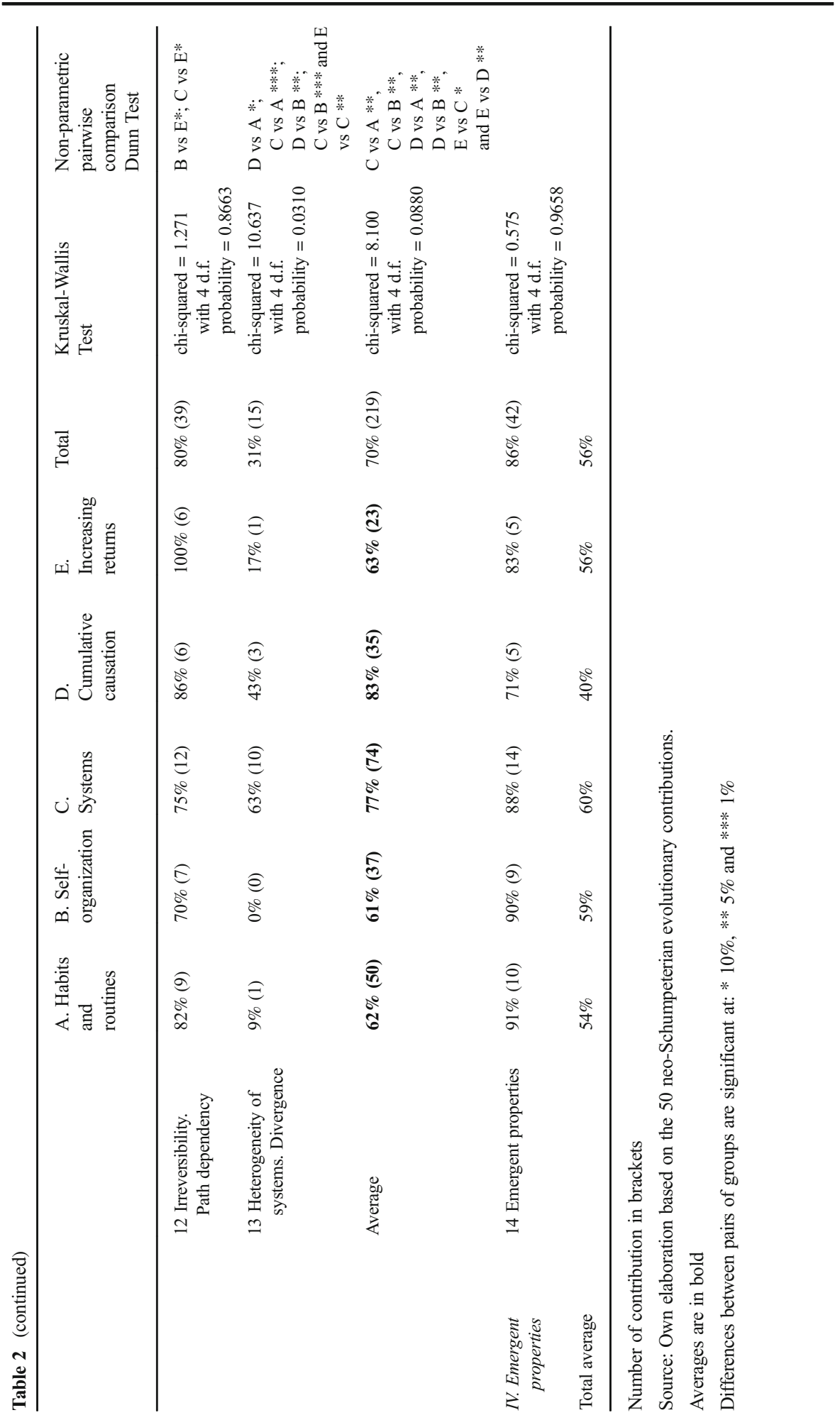


them. The attributes that are most often present in the literature independent from the group are learning and adaptation as sources of heterogeneity, indeterminacy and uncertainty, far from equilibrium dynamics and emergent properties, although, in this last case, there are differences between the groups with respect to the kind of emergent properties stressed. In contrast, the attribute of creative capacity as a source of heterogeneity is mostly discarded by all groups. The other attributes are highlighted differentially by each group.

The following is a description of the extent in which each dimension and attribute of complexity is mentioned by the five different groups of contributions.

\subsection{Micro-heterogeneity}

On average, habits and routines and self-organization groups mention more frequently micro heterogeneity dimension of complexity vis á vis the others groups. As opposed to this, the cumulative causation and increasing returns groups pay less attention to heterogeneity and the group of systems refers to this dimension of complexity with the same frequency as the total average of contributions (see average of the first dimension in Table 2).

The dimension micro heterogeneity considers two attributes: the differentiating strategies of agents endowed with creative capacity, and heterogeneity derived from learning and adaptation processes in different evolutionary paths. The former is less mentioned than the last one in the average. In particular, the attribute of microheterogeneity derived from Schumpeterian entrepreneurial behavior is mentioned almost exclusively by habits and routines and self-organization groups of contributions. The attribute learning, adaptation and routines as a source of heterogeneity has a high incidence in all groups, showing that it is a common attribute reflecting a feature of all evolutionary streams (see Table 2).

In the habits and routines strand, the idea that entrepreneurs adopt creative behaviors without notice can be found in Mathews (2002:38), when vindicating Schumpeter's conception of the "creative gales of destruction", initiated by "entrepreneurs who break with existing arrangements in order to try out new combinations". In the same vein, Zollo and Winter (2002:341) acknowledge that incremental improvements can be accomplished not only through the tacit accumulation of experience but also from "sporadic acts of creativity", implying that creative reactions are a source of heterogeneity along with accumulated capacity over time. Regarding the second attribute, habits and routines group makes the assumption of differentiation strategies based on problem-solving heuristics and leading to the emergence of innovation process. This could be explained by the widespread influence of Nelson and Winter (1982) conception of firms as entities that change their routines, innovate and differentiate themselves when non-trivial problems are discovered. In habits and routines, this line of research has led to the concept of absorption capabilities (Cohen and Levinthal 1989) and, years later, to the idea of dynamic capabilities (Nelson 1991; Teece and Pisano 1994). While the concept of absorption capacity refers to the endogenous capacity of the firm to recognize external knowledge, the idea of dynamic capability considers the variation of capabilities over time. This makes firms heterogeneous on the basis of their own trajectory. 
In self-organization group, closer to the Hayekian tradition, Foster highlights the importance of the first attribute. He states that "adaptation is more than natural selection-it involves creativity" and maintains that, as long as imagination and creativity are required, "the evolution of economic systems depends on entrepreneurs and inventors/innovators coming up with new products and/or processes" (Foster 2005: 877-882). However, for the contributions of the self-organization group, the generation of micro-heterogeneity is mainly attributable to the results of the learning process and selection rather than the presence of agents endowed with creative ability. Aldrich et al. (2008:584) emphasizes the learning process in the generation of micro-heterogeneity and, in particular, the "replication of habits, customs, rules and routines, all of which may carry solutions to adaptive problems". In this sense, the competition process leads to a "differential copying of routines, techniques and management procedures", which recalls Metcalfe (2002) suggestion that the generation of micro-diversity not only reflects but also depends on the competitive process.

In the systems contribution group, the existence of interactive learning, userproducer interactions and competence building can explain micro-heterogeneity (Freeman 1995; Lundvall et al. 2002). There is a continuous generation of microdiversity but also a process of resolution of this variety via local knowledge diffusion. These heterogeneities are path dependent, since they are created through interacting learning. According to Edquist and Hommen (1999:69) "learning is one mechanism through which diversity is created. Learning might even be an element in the processes of selection" (p. 69).

In cumulative causation group, micro-heterogeneity can also be seen as a product of learning and adaptation. However, macro and sectoral levels of analysis prevail in most contributions. Therefore, in this group there are few references to micro-heterogeneity.

In increasing returns contributions, micro-heterogeneity is taken into account since they propose that complex systems can be gathered by a set of heterogeneous agents who interact locally in a decentralized manner. This micro-heterogeneity is considered as a result of the processes of learning and adaptation of the agents.

\subsection{Network architecture}

The groups of habits and routines and increasing returns refer to network architecture more frequently than the rest of the groups. It almost plays no role in cumulative causation contributions that make little mention of it. At the same time, in innovation systems contributions as well as in habits and routines, network architecture is mentioned with the same frequency as that in total average (see second dimension average row in Table 2).

It is also important to note that each attribute of network architecture has its own weight in different groups of contributions. There are significant differences between the groups except for the attribute of multiple equilibria, which has little impact on the total of selected contributions (last column of Table 2). In all selforganization contributions, there are references to the attribute of linkages between components, which is particularly relevant in their explanations of emergent properties, but they are also concerned with network topology and partial and 
local information. Habits and routines contributions refer to network topology and modularization in their explanations of organizational routines and the way they structure, although only some contributions mention it. Increasing returns is the group of contributions that draw upon network externalities and multiple equilibria more frequently.

Network architecture plays an important role in habits and routines explanations of learning process and capacity building. In several contributions of this group, the idea of interactions occurring within a network of linkages through which firms access to local information and complement their internal capabilities sets in . Therefore, the firm's individual behavior is partially determined by systemic conditions and idiosyncratic traits. These contributions also refer to network topology regarding modularization and hierarchy in firms' routines as well as their interactions with the environment. ${ }^{11}$ Meanwhile, in habits and routines, institutions bound the behavior of the agents, although micro-interactions based on local learning, and imitation can lead to changes in these rules and institutions. The developed elements on the network architecture help in explaining why these contributions argue for the notion of disequilibrium.

In self-organization, the most mentioned attributes of network architecture are linkages between components, network topology and, to a lesser extent, partial and local information. Linkages between agents are key in most of this group of contributions. Potts (2000) argues that linkages are more important than components for explaining system dynamics. The general analytical form of an evolving economy is a complex graph of the interactions that link agents and rules together. Foster (2005:13) states that firms are networks, and "they differ in terms of the completeness, strength, and particular qualities of their network structures. It is this what determines whether a firm can generate value that yields a profit". The selforganization group conceives the economic structure as a complex system in which connections are incomplete and local (Potts 2001). Local information is articulated into a larger network of interactions (hierarchy), giving rise to collective knowledge. Therefore, self-organization contributions identify multiple scales of analysis (micro-meso-macro). Their opposition to equilibrium relies on their understanding of the architecture of connections as incomplete, which leads to the idea of partial information (Foster 2005).

Among systems group of contributions, the most significant attributes of network architecture are linkages between organizations and local and partial information. Interactions between system components are local, taking into account the complementarity between different pieces of knowledge, incomplete information and bounded rationality of agents. Several contributions related to National Systems of Innovation stress the importance of inter-firm relationships, at the same time as external and intersectoral linkages (Niosi et al. 1993; Freeman 1995). Lundvall et al. (2002) additionally rely on the links and interorganizational interactions, in between universities, research institutes, government agencies, and firms. From the perspective of local innovation systems, the localization of

\footnotetext{
${ }^{11}$ This hierarchy can be found in Nelson and Winter (1982) in the passing from individual learning (skills) to organizational learning (routines).
} 
interactions is also affected by the functioning of the institutions embedded in the territory. The interactions take place in an incomplete architecture of connections, where the information is local and formal or informal linkages are key to account for the learning process (Breschi and Lissoni 2001). Depending on the emphasis given on the chain on sectoral systems, the interactions are captured mainly through the concept of supplier-customer interaction (Malerba 2002). In the discussion held within evolutionary geography on the role of territory, various contributions have stressed the need to expand the dimensionality of space beyond the geographical one. In particular, Boschma (2005) and Antonelli (2011) are interested in analyzing the network architecture in multi-dimensional space in a framework of an incomplete network of connections. Partial and asymmetric information is seen by authors of this group as an inherent feature of the innovation process. Metcalfe (1995) stresses that innovations and information asymmetries are one and the same phenomenon.

Cumulative causation contributions consider that interactions are mostly global, since the structural conditions act as a signal to all agents within a system. Therefore, this dimension of complexity almost plays no role in their explanations of complex dynamics, at least at the firm level. In this context, the possibility of emerging externalities that trigger growth and diversify the productive structure relies on the characteristics of the productive structure itself.

Finally, increasing returns group of contributions stress the attributes of partial and local information, network externalities and multiple equilibrium within network architecture dimension of complexity. The underlying network structure explains the aggregate phenomena. As Kirman (1997:340) says, the network "evolves over time with the evolution of the players and there is a continual feedback from one to the other". The most important factor to consider is indeed how behavior changes as agents interact through a network and how networks themselves evolve endogenously. As long as the location of the firms determines the connection and the network architecture, there cannot be a global controller. In turn, interactions - to which firms can access through specific linkages - are a key factor. In this group, some authors suggest that interactions allow a stimulus to one individual to be magnified by its dispersion through the network (Durlauf 1998). In this context, the network externalities are sources of increasing returns and, under increasing returns, many outcomes are possible and significant circumstances become magnified by positive feedback. Simultaneously, the idea of multiple equilibria is a predictable consequence of allocation problems with increasing returns (Arthur 1989).

\subsection{Interactions, disequilibrium and divergence}

The dimension interactions, disequilibrium and divergence is mentioned more frequently by systems and cumulative causation groups (see average of third dimension in Table 2). There are some exceptions referred to the attributes indeterminacy and uncertainty, and irreversibility and non-ergodic path dependence, mentioned by all streams. In particular, the heterogeneity of systems is only significant in the systems and the cumulative causation groups, and is barely referred to by the other groups. At the same time, far-from-equilibrium dynamics acquires greater importance in self- 
organization and cumulative causation groups, which are further away from the traditional idea of equilibrium. Cumulative causation and increasing returns make more references that the average to positive feedbacks attribute. Finally, coevolution is very important in cumulative causation and systems groups that show greater interest in the aggregate level of analysis.

In habits and routines, relevant attributes of this dimension vis-à-vis the other groups are indeterminacy and uncertainty and irreversibility and path dependency. The attribute indeterminacy and uncertainty appears linked to far-from-equilibrium dynamics in the statement of Patel and Pavitt (1997:143) "technological artifacts, and the organizational and economic worlds in which they are embedded, comprise so many variables and interactions that it is impossible fully to model, predict, and control their behaviour". Thus, "certainty about the future, probabilistic risk, and optimization are therefore impossible". As a corollary, individuals must rely on habits and rules in situations of radical uncertainty (Hodgson 1998).

Simultaneously, in self-organization the most relevant attributes are far from equilibrium dynamics, indeterminacy and uncertainty. The attribute of indeterminacy and uncertainty can be found in the nature of knowledge and its accumulation processes (Metcalfe 2002:9-10): "It is because knowledge is used but not used up, that ideas feed inexorably on ideas, which make increasing returns in the production of ideas to be of far greater importance than increasing returns in the production of goods and services". In this vein, knowledge "defies equilibrium by maintaining a potential for change that is ever present" (Metcalfe 2002:7-8). From this perspective, markets are institutions that facilitate change and thus "they are devices for keeping the economy ordered but out of equilibrium, they are the frameworks which shape ongoing structural change". This gives way to the idea that "capitalist economies are restless, they never can be in equilibrium, and they are driven at root by experiments in novelty creation" (Metcalfe 2002:14).

In systems, cumulative causation and increasing returns, interactions between components can generate positive feedbacks that amplify individual responses, resulting in emergent aggregate dynamics. In this sense, the interactions between firms and its environment lead to aggregate dynamics and to persistent heterogeneity.

In systems, positive feedbacks, indeterminacy and uncertainty and, mainly, heterogeneity of systems and divergence are the most relevant attributes of this dimension, specially, vis-à-vis the other groups. In systems, the responses of each firm to changes in environmental conditions - due to changes made by other co-located firms- lead to answers that can be amplified at the system level. As such, interactions that generate externalities multiply through feedbacks leading to increasing returns and divergent dynamics. Nevertheless, feedbacks assume specific forms in different contributions. According to Asheim and Coenen (2005), they are derived from interactive learning. Meanwhile, Antonelli (1999) emphasises feedbacks between occurrence of problems and accumulation of skills.

Regarding meso-heterogeneity and divergence, there are various positions in the systems contributions. Asheim and Coenen (2005) suggest that there are significant differences in the dynamics systems, focusing on the existence of blockages in interactive learning processes while, according to Breschi and Lissoni (2001), those differences depend on the possibility of appropriation of knowledge spillovers. Freeman (1995:15) addresses the problem of "uneven development of the world economy and 
divergence in growth rates". He considers that these differences between systems depend on a number of factors, such as the strength of user-producer and subcontractor network linkages, strength of incentives to innovate at enterprise level involving both management and workforce, intensity of experience of competition in international markets, proportion of engineering graduates, among others.

In cumulative causation groups of contributions, the most important attributes of this dimension are positive feedbacks and coevolution. These contributions identify feedbacks between aggregate variables, i.e., Kaldor-Verdoorn dynamics. Dosi (1982) is interested in the feedbacks between technology and the environment in the selection processes. Saviotti (2001) focuses on the feedbacks between the production system and demand, i.e., customer feedback. Dosi et al. (2010) explore the feedbacks between aggregate demand and technological change. Lastly, Metcalfe et al. (2006) point out that positive feedbacks augment growth within and between sectors.

As in all cases where feedback processes may play an important role, the contributions in cumulative causation stress the possibility of lock-in situations caused by nonlinear interactions. In particular, they refer to learning and adaptation processes that lead to co-evolution between demand and technological and production conditions. Discussing the issues of co-evolution, Saviotti and Pyka (2004:33) argue that there exists "complementarity between efficiency growth and variety growth in economic development. By increasing efficiency in each sector, the rate of creation of new sectors, and thus of variety creation in the whole economy, will grow". Cimoli et al. (2010:13) states that this co-evolution is mediated by sectoral differences in income elasticity of demand. The authors argue that "it is reasonable to expect that an economic structure with a higher participation of technology-intensive sectors would be abler to react and exploit trade opportunities arising from changes in world demand". Finally, from the perspective of agent-based models, Dosi et al. (2010) emphasize the coevolution of micro- and macro variables.

For Cimoli et al. (2010:12), feedbacks and path-dependence explain the competitive differences, the paths of development and underdevelopment, and the divergence between national systems. They maintain that "cumulative forces related to increasing returns and path-dependency contributed to reinforce technological backwardness and to the loss in competitiveness, thereby leading to more acute divergence". In the same direction, Fagerberg and Verspagen (2002:1293) indicate that in the development paths of countries there coexists divergence processes led by the emergence of new sectors or products (radical innovations) and periods of convergence processes led by imitation and catch-up processes.

In increasing returns, the attributes of positive feedbacks, such being indeterminacyand uncertainty, and irreversibility and non-ergodic path dependence call for further attention. In these contributions, positive feedbacks generate phase transitions that lead from one attractor to another and take the form of increasing returns, network economies, and externalities of different types. According to Durlauf (1998), path dependence is a dynamic version of positive feedbacks that leads, together with network externalities, to increasing returns. In this group, technical interrelatedness, along with economies of scale, and quasi-irreversibility of investment explain why a technology may become 'locked in' as the dominant arrangement (David 1985). Discussing these issues of lock-in, Arthur (1989:117) poses two properties: 
"inflexibility in that once an outcome (a dominant technology) begins to emerge it becomes progressively more 'locked in'; and non-ergodicity in that historical 'small events' are not averaged away and 'forgotten' by the dynamics -they may decide the outcome". Likewise, from a managerial perspective, Silverberg et al. (1988) stress that the effects of the irreversibility of firms' strategies will also manifest itself in the irreversibility of routines and skills.

\subsection{Emergent properties}

Without due regard to the strand to which selected contributions may belong, almost all of them mention emergent properties (see emergent properties dimension in Table 2). Nevertheless, in each strand the form that emergent properties assume is substantially different.

For instance, habits and routines contributions are focused on differentiation strategies in the competition process resulting from capacities and routines building. Therefore, the generation of new habits and routines that regulate the competition process are stressed in this group. From a micro economic perspective, firms change their routines in order to deal with problems or to discover new ones. As a consequence, new rules and habits are instituted and emerge, which shape the competition process. This group of contributions defines emergent properties in terms of: core capabilities (Cohendet and Llerena 2003), dynamic capabilities (Zollo and Winter 2002), institutions and habits (Hodgson 1998), generation and distribution and circulation of knowledge within a system (Cowan and Foray 1997). Cohendet and Llerena (2003) re-discuss the concept of routine developed by Nelson and Winter, considering it as an emergent property. They affirm it is of paramount importance to identify the location of routines -the cognitive, organizational and motivational ones- within the organization, while understanding the structure and incentive scheme of firms. Thus, the local context in which the routines emerge plays a significant role. In particular, operational routines and dynamic capabilities emerge in different types of communities with different cognitive, coordination and incentive principles (Cohendet and Llerena 2003). From the institutionalist perspective, Hodgson resorts to the concept of emergent property to define the different level of analysis. He argues that "socio-economic reality has emergent properties at different levels of analysis, but, ultimately, propositions at one level do have to be consistent with those at another. [...] To see the role of the individual in relation to institutions is to focus on the micro aspect. To take the institution as a socially constructed invariant -or emergent property- is a basis for consideration of macroeconomic dynamics and behaviour" (Hodgson 1998; p. 189).

For their part, in the self-organization group two constitutional properties emerge, clearly identified with coordination and order. As Dopfer et al. (2004) posit, what emerges depends on the dimension from which the system is analyzed. Thus, at the micro level, a rule (routine) emerges, at the meso level multiple updates of this rule made by the agents of a population emerge, and at the macro level populations of rules and updates to them emerge. Similarly, Foster (2005:424) stands that "the market rules emerge by an adaptive evolutionary process". At the same time, Metcalfe (2002) stresses that the evolutionary process explains how populations change over time and how structural change emerges, resulting from 
the interaction and interdependence among agents in the competition process. In this case, innovation increases the variety within population which decreases with the selection process. Therefore, there is a concern about order and how it coexists with heterogeneity. Potts (2000:420) depicts in more detail the innovation process, understanding it as an emergent property: "new knowledge emerges by the creation or the destruction of connections, the aggregate density of connections in the total system has changed".

In systems, the global behavior of the innovation system is by itself an emergent property. Edquist and Hommen (1999) explain that saying that they are the result of a historical process within a framework of interdependences of its components. Therefore, innovation systems are a result of a co-evolution between knowledge, institutions, and organizations. In this group, diverse types of systems of innovation emerge: national (Edquist and Hommen 1999), local (Boschma and Lambooy 1999; Breschi and Lissoni 2001), technological (Carlsson and Stankiewicz 1991) and sectoral (Malerba 2002). For example, Malerba (2002:251) poses: "In broader terms, one could say that a sectoral system is a collective emergent outcome of the interaction and coevolution of its various elements".

Meanwhile, in cumulative causation contributions, emergent properties are connected with transformation. According to Saviotti and Pyka (2004), structural change, new sectors and new products, and innovation emerge as a result of a larger disposable income arising from the technological change itself. As these authors say, "economic development is a process in which new activities emerge, old ones disappear, and the weight of all economic activities and their patterns of interaction change" (Saviotti and Pyka 2004, p. 2). In turn, the emergence of new goods implies that preferences cannot be taken as given, but that they are created during the process of economic development. Onthe other hand, as the unintended result of the collective interactions of the agents, new organizational forms, institutions, and technological trajectories emerge.

Finally, the emergent property in increasing returns group of contributions refers to different possibilities of order that emerge from interactions among decentralized agents. More generally, what emerges in this strand is order that is manifested in a particular network structure (Kirman 1997). Specifically, in the field of technology, what emerges is a dominant pattern of technological adoption (Silverberg et al. 1988), which can lead to a lock in (David 1985; Arthur 1989).

\section{Discussion}

As we have seen in the previous section, the five groups of contributions representative of the five strands of neo-Schumpeterian evolutionary economics- differ each other in the extent to which they mention the dimension and attributes of complexity. Concurrently, the differences are related with the topics in which they are interested and the way these topics are linked to the two major concerns of evolutionary economics. First, groups concerned on coordination rely on assumptions related to heterogeneity and networks, and second, groups concerned on transformation stress positive feedbacks, path dependence and divergent dynamics among their ontological assumptions. 
The first case is explained by the assumption made around knowledge circulation and generation, when explaining competition process and coordination. In the contributions made by those groups, references regarding network structure, the way in which actors interact through defined channels and heterogeneity in terms of both the actor's particular aspects and the relationships established with neighbors and the system as a whole seem to appear more frequently. For instance, authors of this group ensure much more relevance to connections between actors than to the capability and skill of each one. Similarly, these connections are used in literature to explain the problems of coordination derived from division of labor. (See Table 3).

Considering the second case, being its central core and concern transformation, assumptions about the process of economic growth and capacity building are required. In this framework, authors used assumptions such as feedback, non-linear relations and the co-evolution developed by complexity theory., These assumptions explain the learning and growth trajectories in both levels, individual agents as well as the whole system. At the same time, co-evolution and feedback phenomena help to clarify divergent dynamics present in growth processes. (See Table 3).

Emergent properties are common to all groups, yet, they are differentiated in what is considered as emergent properties in each case that vary, according to research topics. In the same way, we can observe a correspondence between ontological premises emphasized by each strand and the type of particular phenomena analyzed in each case. Hence, as it will be detailed hereunder, the forms that assume these emergent properties in each strand are deeply related with a major concern that prevails in each case. (See Table 3).

In sum, while all groups share, to some measure, common ontological assumptions and can be conceived under the umbrella of the ontology of complexity, the dimensions

Table 3 Association between ontological asumption, emergent properties and major concern by strand

\begin{tabular}{|c|c|c|c|}
\hline Strands & $\begin{array}{l}\text { Predominant ontological } \\
\text { assumptions }\end{array}$ & Emergent properties & $\begin{array}{l}\text { Predominant } \\
\text { concern }\end{array}$ \\
\hline $\begin{array}{l}\text { Habits and } \\
\text { routines }\end{array}$ & $\begin{array}{l}\text { Heterogeneous agents with creative } \\
\text { capacities, linkages between components }\end{array}$ & $\begin{array}{l}\text { Habits, rules and } \\
\text { routines, capabilities, } \\
\text { institutions }\end{array}$ & Coordination \\
\hline Self-organization & $\begin{array}{l}\text { Linkages between components, network } \\
\text { topology, far-from-equilibrium dynamics, } \\
\text { indeterminacy, uncertainty }\end{array}$ & $\begin{array}{l}\text { Rules, order, new } \\
\text { knowledge, structure } \\
\text { of connections }\end{array}$ & Coordination \\
\hline Systems & $\begin{array}{l}\text { Linkages between components, positive } \\
\text { feedbacks, co-evolution, divergence }\end{array}$ & $\begin{array}{l}\text { Behavior and evolution } \\
\text { of innovation } \\
\text { systems }\end{array}$ & Transformation \\
\hline $\begin{array}{l}\text { Cumulative } \\
\text { causation }\end{array}$ & $\begin{array}{l}\text { Positive feedbacks, co-evolution, } \\
\text { far-from-equilibrium dynamics, } \\
\text { irreversibility and path dependence, } \\
\text { and divergence }\end{array}$ & $\begin{array}{l}\text { Structural change, new } \\
\text { sectors, technological } \\
\text { trajectories }\end{array}$ & Transformation \\
\hline $\begin{array}{l}\text { Increasing } \\
\text { returns }\end{array}$ & $\begin{array}{l}\text { Network externalities, positive feedbacks, } \\
\text { multiple equilibrium, indeterminacy, } \\
\text { irreversibility and path-dependency }\end{array}$ & $\begin{array}{l}\text { Dominant design, } \\
\text { lock-ins, order, } \\
\text { network structure }\end{array}$ & Coordination \\
\hline
\end{tabular}


and especially the attributes they share are presented with very unequal intensity. Groups in some cases show strong differences in terms of the emphasis placed on the issue of coordination vis-à-vis the issue of transformation.

Our main finding is that habits and routines, self-organization, and to some extent increasing returns strands rely mostly on ontological assumptions associated with coordination, while in systems and cumulative causation strands, those attributes of complexity ontology are instead related to transformation.

\section{Conclusions}

In this paper, first we discussed the general idea of complexity from an evolutionary economics perspective by proposing an integrative ontology including different definitions found in the innovation economic literature. In this regard, we proposed a complexity definition based on four ontological dimensions: i) micro-heterogeneity; ii) network architecture; iii) interactions, disequilibrium, divergence; and iv) emergent properties. For each of these dimensions, we identified a set of attributes that define them. In the second section, we proposed a typology of evolutionary contributions based on their core research questions. In the third section, we analyzed to what extent each strand relies on the different dimensions and attributes of an evolutionary complexity ontology. In order to test this point, we proposed an exercise based on a selection of articles and reference searches to identify dimensions and attributes of the ontology of complexity within each of the five evolutionary groups. In the discussion (section 4), we showed that groups of contributions bonded by topics differ in terms of the emphasis they give to each of the attributes of a complex system. In turn, we found that the theoretical backgrounds and major concerns of each strand lead them to focus on some aspects of complexity.

The content analysis allowed to directly arise, in qualitative terms, the differences in how the ontology of complexity is depicted in the different groups. In that direction, and in a broader sense, the paper showed that evolutionary economics share different ontological assumptions associated with complexity. The inclusion of the ontology of complexity sheds new insight on the characteristics and comparability of groups and their theoretical roots, which are similar in some cases and divergent in others.

The contribution of the paper is to show that complexity can also be useful to point out the profound differences between evolutionary strands and the divergent paths that can arise in the coming years. We propose that these differences reflect deeper issues related to two major concerns of economic theory: coordination and transformation. In this context, we find that complexity can act as an umbrella and, at the same time, as a differentiating criterion, as their different ontological assumptions relate differentially to these two concerns. This result implies that an idea of convergence cannot be established between the groups and that when divergent evolutionary paths of 
thought are intersected with the ontology of complexity they can go in a direction contrary to pluralism.

Acknowledgements A previous version of this paper was presented at Schumpeter Society Conference in Montreal, Canada, 2016. We thank the comments received by discussants in that occasion. We also thank the insightful comments received by the anonymous reviewers. They allow to introduce significant changes that improve very much the article. The usual disclaimer applies.

\section{Compliance with ethical standards}

Funding This study was funded by Fondo Nacional de Ciencia y Tecnología de la Agencia Nacional de Promoción Científica y Técnica, Argentina (Grant number: PICT 2012 N0833).

Conflict of interest The authors declare that they have no conflict of interest.

\section{Appendix}

Table 4 Keywords selected for each major topic

\begin{tabular}{|c|c|}
\hline Major topics & Key words \\
\hline Habits and routines & $\begin{array}{l}\text { Habits AND Routines } \\
\text { "Bounded rationality" } \\
\text { Routines } \\
\text { Capabilities OR Capacities OR Skills }\end{array}$ \\
\hline Self-organization & $\begin{array}{l}\text { Self-organization } \\
\text { Self-transformation } \\
\text { "Population dynamics" } \\
\text { "Evolutionary competition" } \\
\text { Order }\end{array}$ \\
\hline Innovation systems & $\begin{array}{l}\text { "Local System of innovation" } \\
\text { "Sectoral System of innovation" } \\
\text { "Regional System of innovation" } \\
\text { "National System of innovation" } \\
\text { "Local innovation System" } \\
\text { "Sectoral innovation System" } \\
\text { "Regional innovation System" } \\
\text { "National innovation System" }\end{array}$ \\
\hline Cumulative causation & $\begin{array}{l}\text { "Cumulative causation" } \\
\text { "Structural change" } \\
\text { Catch-up }\end{array}$ \\
\hline Increasing returns & $\begin{array}{l}\text { "Increasing returns" } \\
\text { Lock-in }\end{array}$ \\
\hline
\end{tabular}

Source: Own elaboration 
Table 5 Contributions included in each group

I. Habits and routines

1 Cohen and Levinthal (1990)

2 Cohendet and Llerena (2003)

3 Cowan and Foray (1997)

$4 \quad$ Hodgson (1998)

$5 \quad$ Mathews (2002)

$6 \quad$ Nelson (1991)

$7 \quad$ Nelson and Winter (2002)

$8 \quad$ Patel and Pavitt (1997)

$9 \quad$ Pavitt (2002)

10 Teece and Pisano

11 Zollo and Winter (2002)

\section{Self-organization}

$12 \quad$ Aldrich et al. (2008)

13 Dopfer et al. (2004)

14 Dosi and Nelson (1994)

$15 \quad$ Foster (2005)

16 Langlois (2003)

17 Loasby (1998)

$18 \quad$ Marengo and Dosi (2005)

19 Metcalfe (2002)

20 Potts (2001)
Absorptive capacity: a new perspective on learning and innovation.

Routines and incentives: the role of communities in the firm.

The economics of codification and the diffusion of knowledge.

The approach of institutional economics.

A resource-based view of Schumpeterian economic dynamics.

Why do firms differ, and how does it matter?

Evolutionary theorizing in economics.

The technological competencies of the world's largest firms: complex and path-dependent, but not much variety.

Innovating routines in the business firm: what corporate tasks should they be accomplishing?

The dynamic capabilities of firms: an introduction.

Deliberate learning and the evolution of dynamic capabilities.

In defence of generalized Darwinism.

Micro-meso-macro.

An introduction to evolutionary theories in economics.

From simplistic to complex systems in economics.

The vanishing hand: the changing dynamics of industrial capitalism.

The organisation of capabilities.

Division of labor, organizational coordination and market mechanisms in collective problem-solving.

Knowledge of growth and the growth of knowledge.

Knowledge and markets.
Administrative science quarterly, 128-152.

Industrial and corporate change, 12(2), 271-297.

Industrial and corporate change, 6(3), 595-622.

Journal of economic literature, 166-192.

Journal of Evolutionary Economics, 12: 29-54

Strategic Management Journal (1986-1998), 12(sp. issue), 61.

Journal of Economic Perspectives, 23-46.

Research policy, 26(2), 141-156.

Industrial and Corporate Change, 11(1), 117-133.

Industrial and corporate change, 3(3), 537-556.

Organization science, 13(3), 339-351.

Journal of Evolutionary Economics, 18(5), 577-596.

Journal of Evolutionary Economics, 14(3), 263-279.

Journal of evolutionary economics, 4(3), 153-172.

Cambridge Journal of Economics, 29(6), 873-892.

Industrial and corporate change, 12(2), 351-385.

Journal of Economic Behavior \& Organization, 35(2), 139-160.

Journal of Economic Behavior \& Organization, $58(2)$, 303-326.

Journal of Evolutionary Economics, 12(1-2), 3-15.

Journal of Evolutionary economics, 11(4), 413-431. 
Table 5 (continued)

\begin{tabular}{lll}
\hline 21 & Witt (1997) & Structural Change and \\
& economics-what is new? & Economic Dynamics, 8(4), \\
& & $489-507$.
\end{tabular}

III. Cumulative causation

22 Cimoli et al. (2010)

23 Dosi (1982)

24 Dosi et al. (2010)

$25 \quad$ Fagerberg and Verspagen (2002)

$26 \quad$ Metcalfe et al. (2006)

27 Saviotti (2001)

28 Saviotti and Pyka (2004)

IV. Innovation systems

29 Anderson and Tushman (1990)

$30 \quad$ Antonelli (1999)

31 Asheim and Coenen (2005)

32 Boschma and Lambooy (1999)

33 Breschi and Lissoni (2001)

34 Carlsson and Stankiewicz (1991)

$35 \quad$ Cooke (2001)

36 Edquist and Hommen (1999)

37 Freeman (1995)

$38 \quad$ Keppler (1997)
Structural change and the BOPconstraint: why did Latin America fail to converge?

Technological paradigms and technological trajectories: a suggested interpretation of the determinants and directions of technical change.

Schumpeter meeting Keynes: A policy-friendly model of endogenous growth and business cycles.

Technology-gaps, innovationdiffusion and transformation: an evolutionary interpretation.

Adaptive economic growth.

Variety, growth and demand.

Economic development by the creation of new sectors.

Technological discontinuities and dominant designs: A cyclical model of technological change.

The evolution of the industrial organisation of the production of knowledge.

Knowledge bases and regional innovation systems: Comparing Nordic clusters.

Evolutionary economics and economic geography.

Knowledge spillovers and local innovation systems: a critical survey.

On the nature, function and composition of technological systems.

Regional innovation systems, clusters, and the knowledge economy.

Systems of innovation: theory and policy for the demand side.

The 'National System of Innovation' in historical perspective.

Industry life cycles.
Cambridge Journal of Economics, 34(2), 389-411.

Research policy, 11(3), 147-162.

Journal of Economic Dynamics and Control, 34(9), 1748-1767.

Research Policy, 31(8), 1291-1304.

Cambridge Journal of Economics, 30(1), 7-32.

Journal of Evolutionary economics, 11(1), 119-142.

Journal of evolutionary economics, 14(1), 1-35.

\section{Administrative science quarterly, 604-633.}

Cambridge journal of economics, 23(2), 243-260.

Research policy, 34(8), 1173-1190.

\section{Journal of evolutionary economics, 9(4), 411-429.}

Industrial and corporate change, 10(4), 975-1005.

Journal of evolutionary economics, 1(2), 93-118.

Industrial and corporate change, 10(4), 945-974.

Technology in society, 21(1), 63-79.

Cambridge Journal of economics, 19(1), 5-24.

Industrial and corporate change, 6, 145-182. 
Table 5 (continued)

\begin{tabular}{|c|c|c|c|}
\hline 39 & Lundvall et al. (2002) & $\begin{array}{l}\text { National systems of production, } \\
\text { innovation and competence building. }\end{array}$ & $\begin{array}{l}\text { Research policy, 31(2), } \\
213-231 .\end{array}$ \\
\hline 40 & Malerba (2002) & $\begin{array}{l}\text { Sectoral systems of innovation and } \\
\text { production. }\end{array}$ & $\begin{array}{l}\text { Research policy, 31(2), } \\
\text { 247-264. }\end{array}$ \\
\hline 41 & Pavitt (1984) & $\begin{array}{l}\text { Sectoral patterns of technical change: } \\
\text { towards a taxonomy and a theory. }\end{array}$ & $\begin{array}{l}\text { Research policy, 13(6), } \\
343-373 \text {. }\end{array}$ \\
\hline 42 & Metcalfe (1995) & $\begin{array}{l}\text { Technology systems and technology } \\
\text { policy in an evolutionary framework. }\end{array}$ & $\begin{array}{l}\text { Cambridge Journal of } \\
\text { Economics, 19(1), 25-46. }\end{array}$ \\
\hline 43 & Niosi et al. (1993) & $\begin{array}{l}\text { National systems of innovation: in } \\
\text { search of a workable concept. }\end{array}$ & $\begin{array}{l}\text { Technology in society, } 15(2) \text {, } \\
207-227 .\end{array}$ \\
\hline 44 & $\begin{array}{l}\text { Utterback and Suárez } \\
\text { (1993) }\end{array}$ & $\begin{array}{l}\text { Innovation, competition, and } \\
\text { industry structure. }\end{array}$ & Research policy, 22(1), 1-21. \\
\hline \multicolumn{4}{|c|}{ V. Increasing returns } \\
\hline 45 & Arthur (1989) & $\begin{array}{l}\text { Competing technologies, increasing } \\
\text { returns, and lock-in by historical } \\
\text { events }\end{array}$ & $\begin{array}{l}\text { The economic journal, } \\
116-131\end{array}$ \\
\hline 46 & David (1985) & $\begin{array}{l}\text { Clio and the Economics of } \\
\text { QWERTY }\end{array}$ & $\begin{array}{l}\text { The American economic } \\
\text { review, 332-337 }\end{array}$ \\
\hline 47 & Durlauf (1998) & $\begin{array}{l}\text { What should policymakers know } \\
\text { about economic complexity? }\end{array}$ & $\begin{array}{l}\text { Washington Quarterly, 21(1), } \\
155-165\end{array}$ \\
\hline 48 & Kirman (1997) & The economy as an evolving network & $\begin{array}{l}\text { Journal of evolutionary } \\
\text { economics, 7(4), 339-353 }\end{array}$ \\
\hline 49 & $\begin{array}{l}\text { Silverberg et al. } \\
\text { (1988) }\end{array}$ & $\begin{array}{l}\text { Innovation, diversity and diffusion: a } \\
\text { self-organisation model }\end{array}$ & $\begin{array}{l}\text { The Economic Journal, } \\
\text { 1032-1054 }\end{array}$ \\
\hline 50 & Young (2009) & $\begin{array}{l}\text { Innovation diffusion in } \\
\text { heterogeneous populations: } \\
\text { Contagion, social influence, and } \\
\text { social learning }\end{array}$ & $\begin{array}{l}\text { The American economic } \\
\text { review, 1899-1924 }\end{array}$ \\
\hline
\end{tabular}

Source: Own elaboration based on the 50 neo-Schumpeterian evolutionary contributions

Table 6 Results from different clustering methods. \% of overlap between original (strands) and two alternative clustering methos

\begin{tabular}{lllll}
\hline Strand & Label & $\begin{array}{l}\text { Number of } \\
\text { contributions }\end{array}$ & $\begin{array}{l}\text { Markov } \\
\text { clustering }\end{array}$ & $\begin{array}{l}\text { Modularity class } \\
\text { (average) }\end{array}$ \\
\hline 1 & Habits and routines & 11 & $81.82 \%$ & $67.88 \%$ \\
2 & Self-organization & 10 & $50.00 \%$ & $59.33 \%$ \\
3 & Cumulative causation & 7 & $42.86 \%$ & $42.86 \%$ \\
4 & Systems & 16 & $100.00 \%$ & $63.33 \%$ \\
5 & Increasing returns & 5 & $60.00 \%$ & $92.00 \%$ \\
\hline
\end{tabular}

Source: Own elaboration based on the 50 neo-Schumpeterian evolutionary contributions 


\section{References}

Aldrich HE, Hodgson GM, Hull DL et al (2008) In defense of generalized Darwinism. J Evol Econ 18:577596. doi:10.1007/s00191-008-0110-z

Anderson P, Tushman ML (1990) Technological discontinuities and dominant designs: a cyclical model of technological change. Adm Sci Q 35:604-633. doi:10.2307/2393511

Antonelli C (1999) The evolution of the industrial organisation of the production of knowledge. Camb J Econ 23:243-260. doi:10.1093/cje/23.2.243

Antonelli C (2011) Handbook on the economic complexity of technological change. Edward Elgar Publishing Arthur WB (1989) Competing technologies, increasing returns, and lock-in by historical events. Econ J 99: 116-131. doi: $10.2307 / 2234208$

Arthur WB (1994) Positive feedbacks in the economy. McKinsey Q 81-81

Arthur WB (1999) Complexity and the economy. Science 284:107-109. doi:10.1126/science.284.5411.107

Arthur WB (2009) The nature of technology: what it is and how it evolves. Penguin Adult

Arthur WB (2014) Complexity and the economy. Oxford Univ Pr, Oxford

Arthur WB, Durlauf SN, Lane DA (1997) The economy as an evolving complex system II. Addison-Wesley

Asheim BT, Coenen L (2005) Knowledge bases and regional innovation systems: comparing Nordic clusters. Res Policy 34:1173-1190. doi:10.1016/j.respol.2005.03.013

Boschma R (2005) Proximity and innovation: a critical assessment. Reg Stud 39:61-74. doi:10.1080 /0034340052000320887

Boschma RA, Lambooy JG (1999) Evolutionary economics and economic geography. J Evol Econ 9:411429. doi: $10.1007 / \mathrm{s} 001910050089$

Boschma R, Martin RL (2010) The handbook of evolutionary economic geography. Edward Elgar Publishing

Breschi S, Lissoni F (2001) Localised knowledge spillovers vs. innovative milieux: knowledge "tacitness" reconsidered. Pap Reg Sci 80:255-273

Cantner U, Hanusch H, Klepper S (2000) Economic evolution, learning, and complexity. Springer

Carlsson B, Stankiewicz R (1991) On the nature, function and composition of technological systems. J Evol Econ 1:93-118. doi:10.1007/BF01224915

Cimoli M, Porcile G, Rovira S (2010) Structural change and the BOP-constraint: why did Latin America fail to converge? Camb J Econ 34:389-411. doi:10.1093/cje/ben060

Cohen WM, Levinthal DA (1989) Innovation and learning: the two faces of R \& D. Econ J 99:569-596

Cohen WM, Levinthal DA (1990) Absorptive capacity: a new perspective on learning and innovation. Adm Sci Q:128-152

Cohendet P, Llerena P (2003) Routines and incentives: the role of communities in the firm. Ind Corp Chang 12:271-297. doi:10.1093/icc/12.2.271

Cooke P (2001) Regional innovation systems, clusters, and the knowledge economy. Ind Corp Chang 10:945974. doi:10.1093/icc/10.4.945

Cowan R, Foray D (1997) The economics of codification and the diffusion of knowledge. Ind Corp Chang 6: 595-622. doi:10.1093/icc/6.3.595

Cowan R, Jonard N (2004) Network structure and the diffusion of knowledge. J Econ Dyn Control 28:15571575. doi:10.1016/j.jedc.2003.04.002

David PA (1985) Clio and the economics of QWERTY. Am Econ Rev 75:332-337

Davis JB (2008) The turn in recent economics and return of orthodoxy. Camb J Econ 32:349-366. doi:10.1093/cje/bem048

Day RH (1994) Complex economic dynamics. An introduction to dynamical systems and market mechanisms, vol 1. MIT Press, Cambridge

Dopfer K (2005) The evolutionary foundations of economics. Cambridge University Press

Dopfer K (2012) The origins of meso economics. J Evol Econ 22(1):133-160

Dopfer K, Potts J (2009) On the theory of economic evolution. Evol Institutional Econ Rev 6:23-44

Dopfer K, Foster J, Potts J (2004) Micro-meso-macro. J Evol Econ 14:263-279. doi:10.1007/s00191-0040193-0

Dosi G (1982) Technological paradigms and technological trajectories. Res Policy 11:147-162. doi:10.1016 /0048-7333(82)90016-6 
Dosi G (2013) Innovation, evolution, and economics: where we are and where we should go. In: Fagerberg J, Boschma R, Andersen E (eds) Innovation studies: evolution and future challenges. Oxford University Press, Oxford, pp 111-113

Dosi G, Orsenigo L (1988) Coordination and transformation: an overview of structures, behaviours and change in evolutionary environments. Technical change and economic theory, 13-37

Dosi G, Kaniovski Y (1994) On "badly behaved” dynamics. J Evol Econ 4:93-123

Dosi G, Nelson RR (1994) An introduction to evolutionary theories in economics. J Evol Econ 4:153-172

Dosi G, Winter S (2002) Interpreting economic change: evolution, structures and games. In: The economics of choice, change, and organizations. Edward Elgar Publishers, Cheltenham, pp 337-353

Dosi G, Freeman C, Nelson RR, et al (1988) Technical change and economic theory. Pinter Publishers

Dosi G, Fagiolo G, Roventini A (2010) Schumpeter meeting Keynes: a policy-friendly model of endogenous growth and business cycles. J Econ Dyn Control 34:1748-1767. doi:10.1016/j.jedc.2010.06.018

Durlauf SN (1998) What should policymakers know about economic complexity? Wash Q 21:155-165. doi:10.1080/01636609809550300

Durlauf SN (2005) Complexity and empirical economics*. Econ J 115:F225-F243. doi:10.1111/j.14680297.2005.01003.x

Earl PE, Wakeley T (2010) Alternative perspectives on connections in economic systems. J Evol Econ 20: $163-183$

Edquist C, Hommen L (1999) Systems of innovation: theory and policy for the demand side1. Technol Soc 21: 63-79. doi:10.1016/S0160-791X(98)00037-2

Fagerberg J, Verspagen B (2002) Technology-gaps, innovation-diffusion and transformation: an evolutionary interpretation. Res Policy 31:1291-1304. doi:10.1016/S0048-7333(02)00064-1

Fontana M (2013) Pluralism(s) in economics: lessons from complexity and innovation. A review paper J Evol Econ 24:189-204. doi:10.1007/s00191-013-0333-5

Foss NJ (1994) Realism and evolutionary economics. J Soc Evol Syst 17(1):21-40

Foster J (2005) From simplistic to complex systems in economics. Camb J Econ 29:873-892. doi:10.1093 /cje/bei083

Foster J, Metcalfe JS (2003) Frontiers of evolutionary economics: competition, self-organization, and innovation policy. Edward Elgar Publishing

Freeman C (1995) The "National System of innovation" in historical perspective. Camb J Econ 19:5-24

Frenken K (2006) Innovation, evolution and complexity theory. Edward Elgar Publishing

Helbing D, Kirman A (2013) Rethinking economics using complexity theory. Social Science Research Network, Rochester

Hodgson GM (1998) The approach of institutional economics. J Econ Lit 36:166-192

Hodgson GM (2004) Darwinism, causality and the social sciences. J Econ Methodol 11:175-194. doi:10.1080 $/ 13501780410001694118$

Hodgson GM, Stoelhorst JW (2014) Introduction to the special issue on the future of institutional and evolutionary economics. J Inst Econ 10:513-540. doi:10.1017/S1744137414000393

Holt RP, Rosser Jr JB, Colander D (2011) The complexity era in economics. Review of Political Economy, 23(3):357-369

Jacomy M, Venturini T, Heymann S, Bastian M (2014) ForceAtlas2, a Continuous Graph layout algorithm for handy network visualization designed for the Gephi software. PLoS One 9:e98679. doi:10.1371/journal. pone.0098679

Keppler S (1997) Industry life cycle. Ind Corp Chang 6:145-181

Kirman A (1997) The economy as an evolving network. J Evol Econ 7:339-353. doi:10.1007/s001910050047

Kirman A (2010) Complex economics: individual and collective rationality. Routledge

Langlois RN (2003) The vanishing hand: the changing dynamics of industrial capitalism. Ind Corp Chang 12: 351-385. doi:10.1093/icc/12.2.351

Loasby BJ (1998) The organisation of capabilities. J Econ Behav Organ 35:139-160. doi:10.1016/S01672681(98)00056-0

Lundvall B- $\AA$ (1992) National systems of innovation. Anthem Press

Lundvall B-Å, Johnson B, Andersen ES, Dalum B (2002) National systems of production, innovation and competence building. Res Policy 31:213-231. doi:10.1016/S0048-7333(01)00137-8

Mäki, U. (Ed.). (2001). The economic world view: Studies in the ontology of economics. Cambridge University Press

Malerba F (2002) Sectoral systems of innovation and production. Res Policy 31:247-264. doi:10.1016/S00487333(01)00139-1

Marengo L, Dosi G (2005) Division of labor, organizational coordination and market mechanisms in collective problem-solving. J Econ Behav Organ 58:303-326. doi:10.1016/j.jebo.2004.03.020

Martin R, Sunley P (2007) Complexity thinking and evolutionary economic geography. J Econ Geogr 7:573601. doi:10.1093/jeg/lbm019 
Mathews JA (2002) A resource-based view of Schumpeterian economic dynamics. J Evol Econ 12:29-54. doi:10.1007/s00191-002-0106-Z

Metcalfe JS (1995) Technology systems and technology policy in an evolutionary framework. Camb J Econ $19: 25-46$

Metcalfe JS (2002) Knowledge of growth and the growth of knowledge. J Evol Econ 12:3-15. doi:10.1007 /s00191-002-0107-y

Metcalfe JS (2010) Complexity and emergence in economics: the road map from smith to Hayek (via Marshall and Schumpeter). Hist Econ Ideas XVIII:45-75

Metcalfe JS, Foster J, Ramlogan R (2006) Adaptive economic growth. Camb J Econ 30:7-32. doi:10.1093 /cje/bei055

Nelson RR (1991) Why do firms differ, and how does it matter? Strateg Manag J 12:61-74. doi:10.1002 /smj.4250121006

Nelson RR (1993) National innovation systems: a comparative analysis. Oxford University Press

Nelson RR, Winter SG (1982) An evolutionary theory of economic change. Harvard University Press

Nelson RR, Winter SG (2002) Evolutionary theorizing in economics. J Econ Perspect 16:23-46. doi:10.1257 $/ 0895330027247$

Niosi J, Saviotti P, Bellon B, Crow M (1993) National systems of innovation: in search of a workable concept. Technol Soc 15:207-227. doi:10.1016/0160-791X(93)90003-7

Patel P, Pavitt K (1997) The technological competencies of the world's largest firms: complex and pathdependent, but not much variety. Res Policy 26:141-156. doi:10.1016/S0048-7333(97)00005-X

Pavitt K (1984) Sectoral patterns of technical change: towards a taxonomy and a theory. Res Policy 13:343373. doi:10.1016/0048-7333(84)90018-0

Pavitt K (2002) Innovating routines in the business firm: what corporate tasks should they be accomplishing? Ind Corp Chang 11:117-133. doi:10.1093/icc/11.1.117

Potts J. (2000). The new evolutionary microeconomics: complexity, competence and adaptive behaviour

Potts J (2001) Knowledge and markets. J Evol Econ 11:413-431. doi:10.1007/PL00003865

Potts J. (2010). Ontology in economics. In Theory and applications of ontology: philosophical perspectives (pp. 277-285). Springer, Netherlands

Robert V, Yoguel G (2016) Complexity paths in neo-Schumpeterian evolutionary economics, structural change and development policies. Struct Chang Econ Dyn 38:3-14. doi:10.1016/j.strueco.2015.11.004

Rosser JB (1999) On the complexities of complex economic dynamics. J Econ Perspect 13:169-192

Saviotti PP (2001) Variety, growth and demand. J Evol Econ 11:119-142. doi:10.1007/PL00003853

Saviotti PP, Pyka A (2004) Economic development by the creation of new sectors. J Evol Econ 14:1-35. doi:10.1007/s00191-003-0179-3

Silva ST, Teixeira AAC (2008) On the divergence of evolutionary research paths in the past 50 years: a comprehensive bibliometric account. J Evol Econ 19:605-642. doi:10.1007/s00191-008-0121-9

Silverberg G, Dosi G, Orsenigo L (1988) Innovation, diversity and diffusion: a self-organisation model. Econ J 98:1032-1054. doi: $10.2307 / 2233718$

Simon HA (1962) The architecture of complexity. Proc Am Philos Soc 106:467-482

Simon HA (1969) The science of the artificial. MIT Press

Simon H (1972) Theories of bounded rationality. In: Decision and organization, Norh Holland, Publishig Company. pp 361-376

Teece D, Pisano G (1994) The dynamic capabilities of firms: an introduction. Ind Corp Chang 3:537-556. doi:10.1093/icc/3.3.537-a

Utterback JM, Suárez FF (1993) Innovation, competition, and industry structure. Res Policy 22:1-21. doi:10.1016/0048-7333(93)90030-L

Vromen J (2004) Conjectural revisionary economic ontology: outline of an ambitious research agenda for evolutionary economics. J Econ Methodol 11:213-247. doi:10.1080/13501780410001694136

Wilson D, Kirman A. (2016). Complexity and Evolution. The MIT Press

Winter SG (2014) The future of evolutionary economics: can we break out of the beachhead? J Inst Econ 10 : 613-644. doi:10.1017/S1744137414000277

Witt U (1997) Self-organization and economics - what is new? Struct Chang Econ Dyn 8:489-507. doi:10.1016/S0954-349X(97)00022-2

Witt U (2014) The future of evolutionary economics: why the modalities of explanation matter. J Inst Econ 10 : 645-664. doi:10.1017/S1744137414000253

Young HP (2009) Innovation diffusion in heterogeneous populations: contagion, social influence, and social learning. Am Econ Rev 99:1899-1924. doi:10.1257/aer.99.5.1899

Zollo M, Winter S (2002) Deliberate learning and the evolution of dynamic capabilities. Organ Sci 13:339351. doi:10.1287/orsc.13.3.339.2780 